\title{
Reflexões sobre hidrelétricas na Amazônia: água, energia e desenvolvimento
} Reflections on hydroelectric dams in the Amazon: water, energy and development

\author{
Bertha Koiffmann Becker \\ Universidade Federal do Rio de Janeiro. Rio de Janeiro, Rio de Janeiro, Brasil
}

\begin{abstract}
Resumo: $\bigcirc$ ensaio discute a implantação de hidrelétricas na Amazônia a partir das relações entre consumo de água e hidroeletricidade em diferentes escalas de análise, pois, se todos os lugares do planeta são afetados por processos globais, eles não o são de modo homogêneo. À escala global, domina o discurso apocalíptico de escassez crescente da água e do aquecimento global, exigindo a redução de emissões de gases de efeito estufa mediante o uso de energias renováveis e novas tecnologias. Na escala nacional, os problemas do Brasil são, pelo contrário, como gerir a abundância de água com justiça social e territorial, e como sustar a perda de $20 \%$ da energia elétrica produzida. Finalmente, é na escala regional - na Amazônia que emergem os maiores problemas: i) o maior paradoxo entre abundância de água e inacessibilidade social ao recurso; ii) grande parte das hidrelétricas planejadas para o país será ali construída, com risco dos graves impactos conhecidos; iii) a cogitada obrigatoriedade da construção de eclusas em todas as hidrelétricas, proposta pelo setor industrial em benefício da navegabilidade dos rios, deverá propiciar, na verdade, o escoamento de commodities produzidas na região Centro-Oeste. Coloca-se, assim, para a sociedade e para o governo, a questão ética se realmente são necessárias tantas hidrelétricas na Amazônia.
\end{abstract}

Palavras-chave: Amazônia. Hidrelétricas. Água. Energia elétrica. Desenvolvimento.

Abstract: The essay discusses the deployment of hydroelectric dams in the Amazon having as a starting point the relations between water and hydropower consumption at different scales of analyses. So, if all parts of the world are affected by global processes, they are not in the same way. The global scale is dominated by the apocalyptic discourse of increasing water scarcity and global warming, requiring the reduction of emissions of greenhouse gases through the use of renewable energy and new technologies. On a Brazilian national scale, the problems are, rather, how to manage the abundance of water with social and territorial justice, and how to stop the loss of $20 \%$ of the electricity produced. Finally, it is at the regional scale - in the Amazon - that major problems arise: i) the biggest paradox between the abundance of water and social inaccessibility to this resource; ii) most of the dams planned for the country will be built there, with the risk of negative impacts already known; iii) the obligation of building sluices at all the proposed dams, suggested by the industrial sector in name of the rivers navigation, will serve, in fact, to export commodities produced in the Brazilian central region. An ethical question is, therefore, posed to society and to Brazilian government: are really needed so many hydroelectric dams in the Amazon?

Keywords: Amazon. Hydroelectric dams. Water. Electric power. Development.

BECKER, Bertha K. Reflexões sobre hidrelétricas na Amazônia: água, energia e desenvolvimento. Boletim do Museu Paraense Emílio Goeldi. Ciências Humanas, v. 7, n. 3, p. 783-790, set.-dez. 2012.

Autor para correspondência: Bertha K. Becker. Avenida Atlântica, 1896, ap. 1301. Rio de Janeiro, RJ, Brasil. CEP 22021-001 (bbecker@acd.ufrj.br). Recebido em 28/06/2012

Aprovado em 12/11/2012

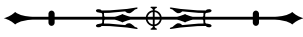


A construção de hidrelétricas - e de toda infraestrutura - na Amazônia têm sido objeto de intensa polêmica e grande variedade de escritos. Não sendo especialista em matéria de energia, o que me proponho neste texto é contribuir para o debate por meio de reflexões sobre as diferentes escalas de análise da questão.

\section{A ESCALA GLOBAL}

A visão da escala global é imprescindível em um mundo globalizado. Como se apresenta à escala global a questão da hidroeletricidade? Ela pode ser encarada sob duas vertentes: a questão da água e a questão da energia.

O discurso sobre a água, por um lado, enfatiza o apocalipse now, ou seja, a crescente escassez de um recurso que terá valor estratégico semelhante ao do petróleo no século $X X$, podendo, inclusive, levar a guerras. Tudo por 'culpa' do Antropoceno, isto é, de uma nova era geológica gerada a partir da revolução industrial, na qual a ação humana modifica a superfície da Terra de tal maneira que ela passa a ser comparável às forças da natureza. Expressões maiores dessa força perversa são o crescimento demográfico e a urbanização.

Outra ênfase do discurso sobre a água é a necessidade da governabilidade global sobre o uso do recurso como solução para o 'apocalipse'. Não existe uma convenção internacional sobre a água, somente para o clima e a biodiversidade, sendo necessário criála. Inúmeros esforços têm sido feitos para discutir essa governança global, sem sucesso.

Vale a pena contrapor alguns fatos ao discurso catastrófico. A escassez de água é diferenciada. É verdade que em várias regiões do globo há baixa disponibilidade do recurso. Mas é possível afirmar que, na maior parte do planeta, há uma diferenciação de acesso social, ou seja, trata-se de uma crise de gestão devido à seleção de investimentos, e não da falta do recurso por culpa do crescimento demográfico e urbano. Ademais, se o discurso catastrófico não conseguiu criar uma governança global para a água, lavrou seu tento ao favorecer, em nome de se evitar o 'desperdício', a instituição de cobrança pelo uso de água a partir das últimas décadas do século $X X$, ou seja, a mercantilização da água na maioria dos países, incluindo o Brasil.

A questão da energia está vinculada às mudanças climáticas e à necessidade drástica da redução de emissões de gases de efeito estufa (GEE), sobretudo o carbono, para reduzir o aquecimento global. Nesse contexto, a questão energética torna-se crucial. O petróleo passa a ser o grande vilão da história pelo montante de gases que emite, bem como o transporte urbano e rodoviário de cargas.

Em nível global, o discurso da 'economia verde' - entendida, grosso modo, como de baixo uso de carbono - emerge como solução, com forte ênfase nas energias renováveis, sobretudo eólica e solar, pois no mundo - e na Europa ainda menos - só 13\% da energia utilizada é renovável. Cresce o uso da energia hidrelétrica, especialmente na Europa, e da bioenergia, hoje correspondendo a apenas 3\% do total. Apesar dessas mudanças, previsões para meados do século estimam que somente $5 \%$ das fontes de energia utilizadas no mundo virão de tecnologias 'pequenas' - solar, fotovoltaica, eólica, biomassa - porque hoje a hidrelétrica é muito mais barata do que a solar, por exemplo. Esta necessita de tecnologia de ponta e anos de pesquisa para se desenvolver, empreendimento dominado pela China, que desbancou a Europa nesse setor.

O discurso da 'economia verde' merece atenção porque, enfatizando cuidados e inovações quanto ao meio ambiente, pode, ao contrário, resultar apenas na ampliação do processo de mercantilização da natureza (Becker, 2001, 2009, 2011). Nesse sentido, a visão nacional é fundamental para melhor avaliar a 'economia verde', pois todos os lugares do planeta são afetados por processos globais direta ou indiretamente -, mas não de modo homogêneo.

\section{A ESCALA NACIONAL}

O problema do Brasil em relação à água, ao contrário do discurso global, é como gerir a abundância. Rios, lagos 
e aquíferos beneficiam o Brasil como um dos maiores detentores de recursos hídricos no planeta.

Quanto à diferenciação de acesso à água, contudo, o Brasil apresenta o mesmo quadro do contexto global: menor disponibilidade geográfica de água no Nordeste em razão da carência relativa ao recurso e, sobretudo, da grande diferença social de acesso ao consumo do recurso. Abastecimento de água satisfatório só existe em $24,1 \%$ dos municípios, sendo necessário ampliar, em 50,6\% deles, as redes e, em 34,6\%, criar novos mananciais. No que tange ao saneamento, a coleta de esgoto só é realizada em $50 \%$ dos municípios, e o tratamento de efluentes apenas em 34,6\%! Por sua vez, é também forte a desigualdade do consumo de água por setor: a irrigação agrícola consome 69\%; a criação de animais, 12\%; as cidades, 10\%; a indústria, 7\%; e o meio rural, 2\% (ANA, 2011). Quanto ao uso não consuntivo (não consumido diretamente), a energia hidrelétrica é a campeã absoluta.

Resulta, assim, que, na matriz energética do Brasil, 45,3\%, quase a metade, provêm de recursos renováveis, um recorde mundial, em grande parte devido à hidroeletricidade (30\%) e também ao etanol proveniente da cana de açúcar (18\%).

Os desafios da desigualdade geográfica e social de acesso à água tendem a se manter, assim como a desigualdade do consumo, crescendo o uso na irrigação e na geração de energia hidráulica e não no saneamento ou na navegação fluvial. Grandes projetos hidrelétricos são concebidos e aprovados para garantir o abastecimento energético para os próximos dez anos e para a internacionalização da Eletrobrás.

Nesse contexto nacional, duas questões se colocam, considerando que, entre 2002-2008, a expansão do consumo energético - 3,63\% para todos os setores - foi menor do que o crescimento da oferta: será tão grande o crescimento do consumo nos próximos dez anos a ponto de necessitar de tantas hidrelétricas? $\bigcirc$ consumo crescente deve ser necessariamente alimentado por hidroeletricidade?
De acordo com o Plano Nacional de Energia (PNE), o consumo final de energia entre os anos de 2005-2030 evoluirá segundo taxas entre $2,6 \%$ e $4,4 \%$ ao ano, configurando quatro cenários: 'na crista da onda', 'surfando a marola', 'pedalinho' e 'náufrago' (Brasil, 2007). Há, assim, alguma incerteza quando ao crescimento do consumo, apesar da inserção das classes C e D no mercado, ainda mais tendo em vista a forte queda no crescimento demográfico e a tendência à estabilidade em não mais de 239 milhões de habitantes em 2030 (Brasil, 2007) (Figura 1).

Quanto às fontes de produção de energia, a 'economia verde' pressiona em favor da utilização de fontes renováveis para reduzir a emissão de gases de efeito estufa. $\bigcirc$ Brasil já diversifica sua matriz com fontes renováveis, embora esteja reduzindo o consumo de etanol de cana-de-açúcar devido à política de valorização do petróleo a ser extraído da camada pré-sal, mantendo baixo o preço da gasolina. $O$ país aqui se depara com uma grande questão: a energia hidrelétrica é renovável, mas com impactos ambientais negativos. Estes decorrem, sobretudo, da migração desordenada e do desmatamento decorrente, e poderiam ser reduzidos quando do próprio planejamento de uma hidrelétrica.

Assim, a diversificação da matriz é desejável, pois é difícil abrir mão de tamanho potencial, mas não a qualquer custo. No Brasil, o maior problema desse setor parece ser o desperdício: $1 / 4$ ou $25 \%$ de perda na geração e distribuição da energia produzida. Uma das alternativas, de baixo custo, para a obtenção de energia no país é a eficiência energética, e não só, ou não tanto, a ampliação da oferta de produção. Essas considerações na escala nacional assumem, entretanto, outra conotação na escala regional.

\section{A ESCALA REGIONAL}

A questão regional do uso da água e da produção de energia hidrelétrica é, sobretudo, uma questão amazônica porque os grandes projetos hidrelétricos do Programa de Aceleração do Crescimento (PAC) serão localizados na Amazônia brasileira, e os projetos da Eletrobrás foram

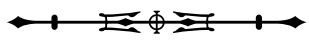




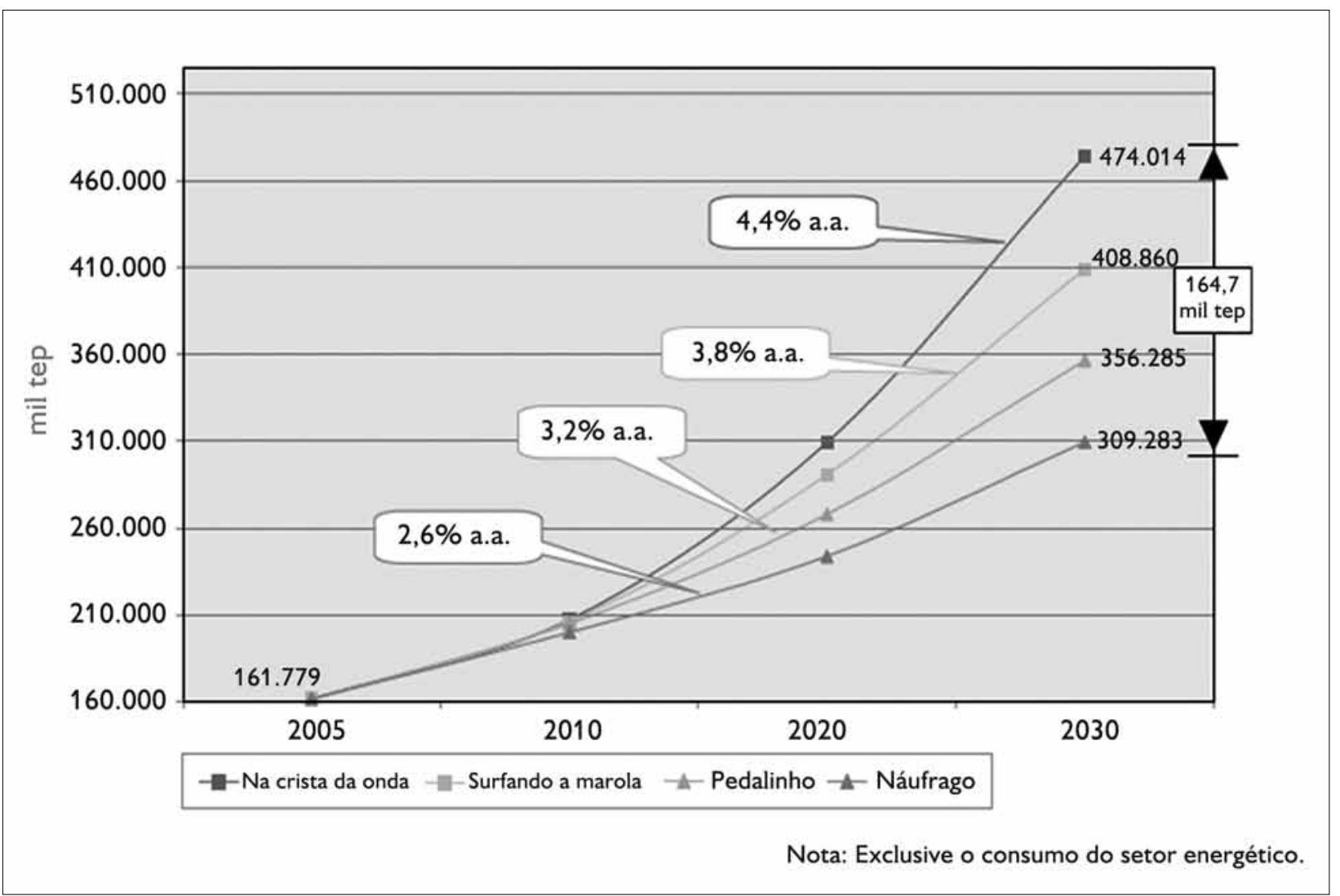

Figura 1. Evolução do consumo final de energia por cenário. Fonte: Brasil (2007).

previstos para a Amazônia sul-americana. Acresce a eventual obrigatoriedade de construir eclusas nas barragens de usinas hidrelétricas (Projeto de Lei 3009/1997) para impedir que inviabilizem a navegação fluvial. Segundo o Ministério dos Transportes (MT), trata-se de um pacote de 27 eclusas, correspondendo a 11,6 bilhões de reais, gastos até a conclusão das obras, prevista para 2018, em seis grandes rios, quatro dos quais localizados na Amazônia: Araguaia, Tocantins, Teles Pires e Tapajós.

Enquanto se propõem megaprojetos para a geração de energia e navegação na Amazônia, configura-se o auge do paradoxo entre a abundância de água e a inacessibilidade social: a água é utilizada especialmente para a produção de energia a ser transportada para outras regiões do país (e para a irrigação nas áreas do agronegócio), enquanto a população não tem acesso à água potável!
A construção de hidrelétricas na região, como se sabe, é intensamente polemizada. No rio Teles Pires, em Mato Grosso, duas usinas já estão em construção (Teles Pires e Colíder) e mais três serão iniciadas em 2013. As usinas do rio Tapajós, em número de quatro, afetarão pequenas unidades de conservação, compensando-se sua redução com a ampliação de parques. Para as terras indígenas afetadas, que são terras da União, propõe-se compensação financeira pela produção de energia. As compensações financeiras são do tipo royalty, pagandose $6,75 \%$, a serem alocados em um fundo destinado a aplicações nessas terras. Para municípios e estados, os royalties são de 3\% para cada um.

A preocupação com a navegação fluvial emerge em um conflito entre os setores de energia e de transporte, pois, pelas regras atuais, o empreendedor de uma hidrelétrica

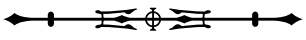


só é obrigado a considerar a viabilidade de uma eclusa se a usina interromper o fluxo de uma hidrovia existente. $\bigcirc$ Ministério dos Transportes, ao defender a obrigatoriedade da construção de eclusas junto às usinas, apresenta como argumentos a histórica apropriação dos recursos hídricos pelo setor energético, sem pensar no seu uso múltiplo; a necessidade de ampliação da navegação fluvial, em vez do transporte rodoviário; e a redução do custo da construção da eclusa em 40\%, caso ocorra simultaneamente à usina. Por sua vez, o Ministério de Minas e Energia argumenta que a construção de eclusas atrasaria os empreendimentos, embora os custos sejam arcados, muitas vezes, por outras fontes; e também que nem todas as barragens construídas travaram a navegabilidade dos rios por não terem eclusas.

$\mathrm{Na}$ verdade, outras questões são mais importantes para esclarecer quais os verdadeiros interesses que movem os grandes projetos (e os conflitos deles decorrentes), e quais os resultados para a nação. A primeira pergunta é: será garantida a internacionalização da Eletrobrás por expansão nos países vizinhos?

Ao que tudo indica, essa expansão não é garantida por, pelo menos, duas razões. Uma delas é a forte competição com a China. No Equador, as três maiores hidrelétricas estão sendo construídas pelos chineses, rompendo a hegemonia das empresas brasileiras Odebrecht e Andrade Gutierrez em relação a esse tipo de obra. A segunda razão é a resistência nacional de países sul-americanos contra empresas brasileiras. É o caso do Peru, onde o Brasil planejou a construção de inúmeras hidrelétricas que foram sustadas. Há exemplos também na Argentina e na Bolívia.

Em suma, não há mais tanta facilidade para a internacionalização da Eletrobrás no continente sulamericano. Não por acaso, a empresa vem atuando na Nicarágua (América Central) e em Moçambique (África). Tal contexto indica a importância que deveria assumir o mercado doméstico de água, recurso estratégico do país, com a possibilidade de uma ampla diversificação do uso, a começar pelo atendimento social.
Outras perguntas estratégicas: são realmente necessárias tantas eclusas para a navegação fluvial e, em última análise, tantas hidrelétricas na Amazônia? Qual sua finalidade?

Há anos, reivindicamos a priorização da navegação fluvial articulada à área e à multimodalidade na região. Mas a navegação deve levar em consideração a demanda da população regional, e não apenas o transporte de cargas e commodities, e ser incentivada mediante obras relativamente simples no leito dos rios. Não é o que ocorre com as propostas atuais.

Diz-se que todos os rios são navegáveis, dependendo da finalidade da navegação, que é gerada por oportunidades econômicas e/ou por planejamento estratégico nacional. A oportunidade econômica usada como justificativa para a intervenção nos rios amazônicos parece ter surgido com a expansão da agropecuária, distante dos portos litorâneos, acentuando as carências de infraestrutura logística do país e tornando exorbitante o custo do transporte rodoviário de grãos. Não por acaso, as propostas de inúmeras hidrelétricas e a obrigatoriedade de eclusas são apoiadas pelo setor privado industrial, por meio do Projeto Norte Competitivo (PNC). Segundo esse megaprojeto, as hidrovias seriam as melhores alternativas para a região amazônica, tendo as ferrovias como segunda opção.

Argumenta-se que a implantação de infraestrutura logística englobando todos os modais de transporte é uma das maiores demandas do setor produtivo brasileiro, e um dos grandes desafios a serem enfrentados pelo Governo Federal. O Brasil tem 63.000 km de rios pouco aproveitados. Dos $43.000 \mathrm{~km}$ considerados navegáveis, somente 15.500 são utilizados comercialmente, o restante sendo praticamente inexplorado. $\bigcirc$ transporte fluvial corresponde apenas a $4 \%$ da carga movimentada - 45 milhões de toneladas -, enquanto as estradas transportam 63\% do total. O potencial mínimo para o transporte de carga nas hidrovias seria, pelo menos, de 180 milhões de toneladas.

$\mathrm{O}$ PNC propõe uma infraestrutura de transporte baseada em eixos de desenvolvimento, que formariam 
um sistema de logística integrado, sem fronteiras estaduais e intermodal, privilegiando aqueles de menor custo. Propõe nove eixos de integração, que permitiriam reduzir os custos logísticos da Amazônia Legal, aumentando sua competitividade. Os eixos principais são a Hidrovia do Madeira, a Hidrovia Juruena-Tapajós e a Rodovia BR-242/ Hidrovia Tocantins (Figura 2). No PNC, o modal hidroviário teria 27 projetos associados, correspondendo a 38\% do total, e a $32,6 \%$ do valor global.

Essa confluência de interesses na navegação fluvial parece favorecer as exportações da agropecuária. Nesse contexto, a construção de eclusas não é considerada obrigatória. As eclusas são vistas como obras de mitigação dos impactos negativos das hidrelétricas, isto é, quando estas impedem a circulação, constituindo um custo adicional. $\bigcirc$ que importa avaliar seria a própria construção das hidrovias num plano integrado de logística. A decisão de construção de uma hidrovia na Amazônia - e também de eclusas - deveria depender de uma avaliação estratégica, e não só de uma avaliação de engenharia. Há que considerar os efeitos que a hidrovia induzirá em termos de mudança no uso do território: se houver

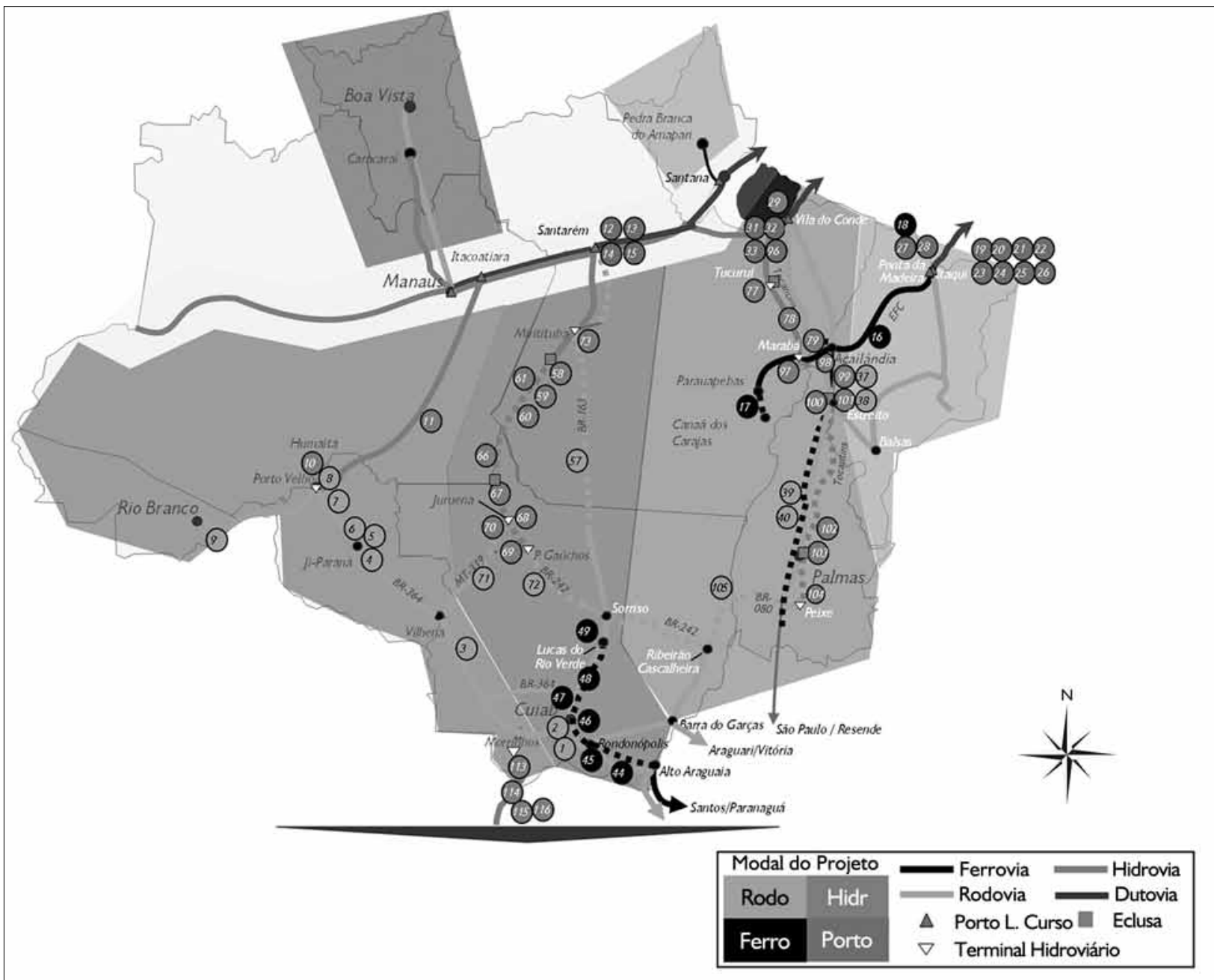

Figura 2. Escala regional: eixos de desenvolvimento do Projeto Norte Competitivo (Confederação Nacional da Indústria). Fonte: Projeto Norte Competitivo (2011).

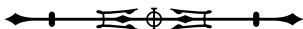




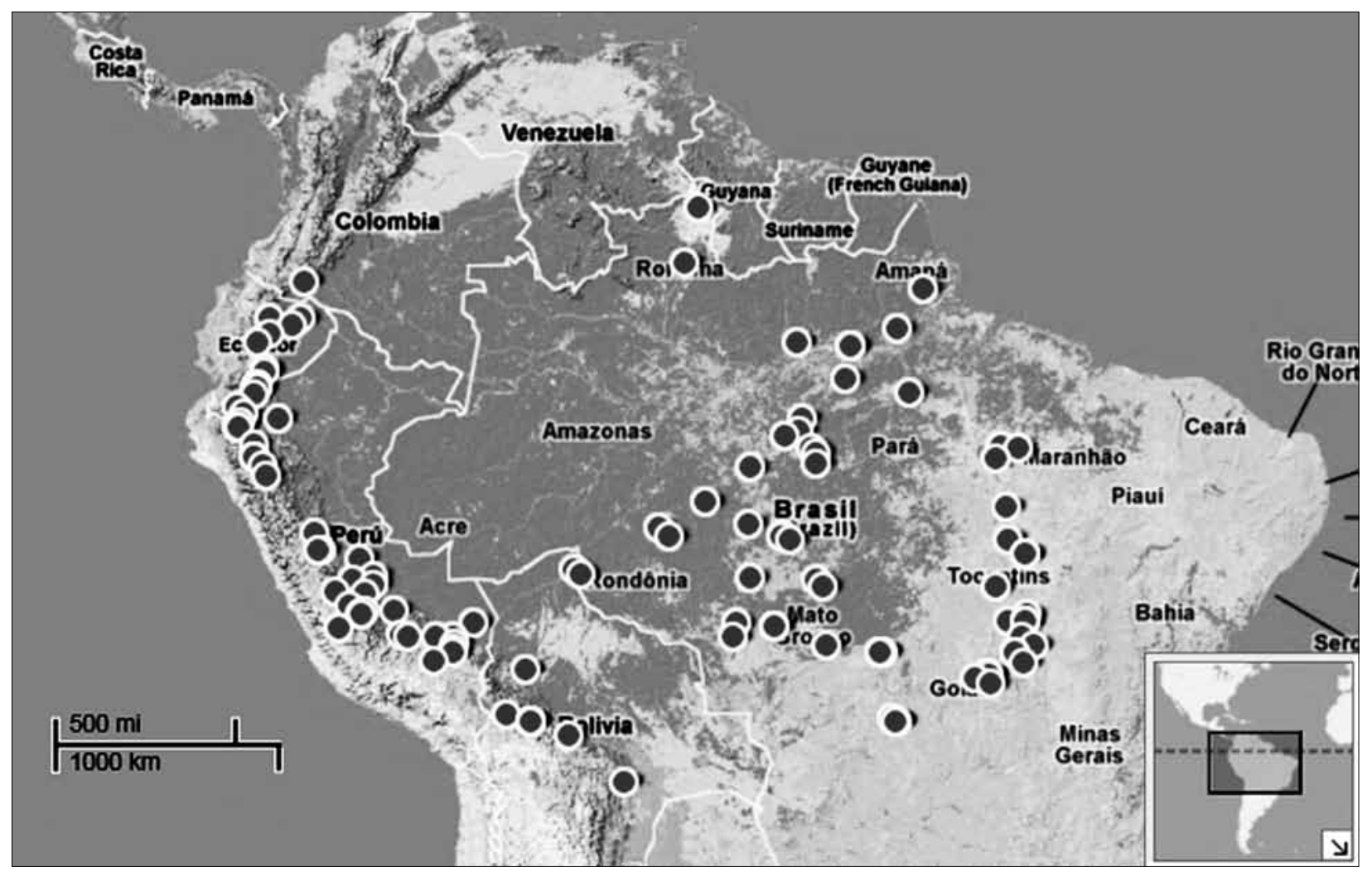

Figura 3. Usinas hidrelétricas planejadas na Amazônia sul-americana. Fonte: Fundación Proteger/International Rivers/Ecoa (s.d.).

demanda social local, a hidrovia pode ser fator crucial para o desenvolvimento; se não houver, o impacto se fará, provavelmente, pelo viés especulativo-financeiro já conhecido, acompanhado da apropriação de terras, da migração desordenada e do desflorestamento.

Em suma, as externalidades geradas por uma hidrovia tendem a ser inferiores às de outros modais, mas seu poder indutor de transformação varia de acordo com as características da logística que proporciona. $\bigcirc$ mesmo raciocínio se aplica à multiplicação de hidrelétricas na Amazônia. Entende-se que a construção de uma ou outra grande hidrelétrica seja necessária para garantir a oferta de energia na escala nacional com uma fonte renovável. Mas a sucessão de hidrelétricas em áreas florestais pouco povoadas e sem base econômica significativa não parece sensata.

Os recursos da Amazônia serão mais uma vez utilizados para abastecer o Centro-Sul e as empresas de alumínio, processo acrescido agora com a construção de hidrovias para escoar soja e carne do Centro-Oeste? Essa nova dinâmica deverá gerar benefícios para a Amazônia? Ou, pelo contrário, à região serão destinados apenas os impactos sociais e ambientais perversos?

A par dos impactos conhecidos historicamente, há outros ainda a conhecer. Estudo recente analisando os planos para a construção de barragens na Bolívia, no Brasil, na Colômbia, no Equador e no Peru contabiliza 151 hidrelétricas no entorno da floresta, com penetrações mais avançadas no Brasil (Figura 3). O estudo afirma que a construção de $60 \%$ delas já causaria a primeira grande quebra na conectividade entre as cabeceiras andinas e a planície amazônica, que passará a receber menos sedimentos, nutrientes e matéria orgânica, afetando a floresta e a migração de peixes (Butler, 2012).

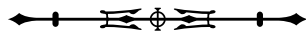


Coloca-se, assim, a questão ética para a sociedade e para o Estado brasileiro: é adequada e justa - para o desenvolvimento da Amazônia - a construção de tantas hidrelétricas para exportar energia e de hidrovias para exportar soja?

\section{CONSIDERAÇÕES FINAIS}

A questão dos recursos hídricos no Brasil não corresponde ao discurso global: não há, no país, falta do recurso - à exceção do Nordeste -, mas, sim, escassez produzida por falta de acesso. Verdadeiro paradoxo se encontra na Amazônia: é detentora de cerca de $18 \%$ da água doce do planeta e a maioria da população não tem acesso à água potável.

O Brasil pode e deve criar um enfoque alternativo ao apocalíptico dominante, reconhecendo que grande parte da escassez é produzida pela seleção de investimentos e por formas de gestão. Elementos de outro enfoque seriam: a) o uso múltiplo da água com prioridade à demanda social e ao saneamento, processo que ampliará o mercado doméstico para investimentos e que também poderá reduzir a orientação atual voltada para grandes empresas e grandes projetos; b) atribuição de alta prioridade à eficiência energética, o que, segundo muitos, reduzirá em 20\% a perda do total de energia produzida, correspondendo à construção de uma outra Itaipu, e poderá baratear o custo da energia para a indústria; c) estímulo a inovações, como a construção de sistemas descentralizados de produção de energia e de práticas de abastecimento de água/saneamento, segundo a potencialidade local, ou o incremento de experimentos a partir de práticas simples de populações rurais e também de parcerias com populações vizinhas em áreas de fronteira.

Nessa perspectiva, há algumas questões institucionais a considerar, envolvendo o resgate do planejamento estratégico para uso múltiplo dos recursos hídricos e para cada um deles no conjunto. A questão nova decorrente da integração sul-americana, incluindo o uso compartilhado de água na bacia amazônica, deve ser regulamentada por acordos bilaterais ou por cooperação múltipla sob comando de uma autoridade regional? É tempo de criar o Instituto do Coração Florestal (amazônico) para construir um pensamento estratégico, visando o desenvolvimento responsável da região e sua contribuição para o país.

\section{REFERÊNCIAS}

AGÊNCIA NACIONAL DE ÁGUAS (ANA). Conjuntura dos Recursos Hídricos do Brasil: informe 2011. Brasília: ANA, 2011.

BECKER, Bertha K. Papel do Estado brasileiro no desenvolvimento da Amazônia. In: VAL, Adalberto Luis; SANTOS, Geraldo Mendes dos (Orgs.). Grupo de Estudos Estratégicos Amazônicos. Manaus: GEEA, 2011. (Caderno de Debates, IV). p. 105-136.

BECKER, Bertha K. Problematizando os serviços ambientais para o desenvolvimento da Amazônia. Uma interpretação geográfica. In: BECKER, Bertha K.; COSTA, Francisco de Assis; COSTA, Wanderley Messias da (Orgs.). Um projeto para a Amazônia no século 21: desafios e contribuições. Brasília: CGEE, 2009. v. 1, p. 87-120.

BECKER, Bertha K. Amazonian frontiers at the beginning of the 21st century. In: HOGAN, Daniel Joseph; TOLMASQUIM, Maurício Tiomno (Eds.). Human dimensions of global environmental change: Brazilian perspectives. Rio de Janeiro: ABC, 2001. v. 1, p. 299-324.

BRASIL. Empresa de Pesquisa Energética (EPE). Plano Nacional de Energia 2030. Rio de Janeiro: EPE, 2007.

BUTLER, Rhett A. Will mega-dams destroy the Amazon? Mongabay. com, 18 abr. 2012. Disponível em: <http://news.mongabay. com/2012/0418-amazon_mega-dams.html>. Acesso em: 29 jun. 2012.

FUNDACIÓN PROTEGER/INTERNATIONAL RIVERS/ECOA. Barragens na Amazônia. s. d. Disponível em: <http://www.damsinfo.org/pt>. Acesso em: 29 jun. 2012.

PROJETO NORTE COMPETITIVO. Confederação Nacional da Indústria (CNI), idealizado pela Ação Pró-Amazônia (Federação das Indústrias da Amazônia Legal). São Paulo, 2011. 